\title{
La nueva concepción de la imagen religiosa
}

\author{
Ma Teresa Gonzalez Vicario
}

La imagen constituye un destacado y, a la vez, complejo tema dentro del arte sacro. En un conocido estudio de Romano Guardini se hace una distinción entre imagen de culto e imagen de devoción: "La imagen de culto no procede de la experiencia interior humana, sino del ser y el gobierno objetivo de Dios; con lo cual no me refiero a ningún procedimiento efectivo del artista, considerado con plena conciencia, sino al germen de sentido del proceso... La imagen de devoción arranca de la vida interior del individuo creyente: del artista y del que hace el encargo, que, a su vez, toman ellos mismos la posición del individuo en generals. 1 . No obstante, esta diferenciación no es tan fácil en la realidad, como afirma el padre José Manuel de Aguilar: «Discusión más teórica que real, pues será difícil encontrar en la práctica ejemplares puros, siendo frecuente la yuxtaposición y mezcla de los caracteres de una y otra. Será distinción útil porque ayudará a matizar los valores intrínsecos o funcionales de una obra de arte $»^{2}$.

A través del tiempo, la imagen ha constituido un importante vehículo para el creyente, un medio material que le acerca a la divinidad, evolucionando y adaptándose a las necesidades artísticas de cada momento.

En la actualidad, la escultura religiosa sigue una doble corriente: aquélla que se mantiene fiel a la tradición y la que, por el contrario, se abre a los nuevos movimientos, porque según afirma el padre José Manuel de Aguilar: "No olvidemos que uno de los objetivos estéticos -comunes a las corrientes del arte actual- ha sido la superación del realismo historicista,

\footnotetext{
' R. GuaRdiNl: "Imagen de culto e imagen de devoción", Carta a un historiador de arte, en Obras, T.I., Madrid, 1981, págs. 337 y 338.

? J.M. de AguiLar, O.P.: Casa de Oración, Madrid, 1967, pág. 127.
} 
del academicismo anodino y frío, del blando sentimentalismo, que dieron tónica a las expresiones plásticas de todo el siglo pasado. Las reacciones provocaron una proliferación de tendencias variadísimas que si delatan muchas veces un anarquismo -casi desintegración- de formas y materias, por otra parte proclaman una inquietud depuradora, una búsqueda inquieta, una aventura liberadora de todo lo que es convencionalismo ${ }^{3}$.

A partir de la celebración del Concilio Vaticano II (1962-1965), se ha operado un radical cambio en la decoración de los templos, advirtiéndose, entre otros aspectos, la ostensible disminución del número de imágenes en los mismos, con el deseo de conseguir una mayor autenticidad religiosa, evitándose aquella excesiva proliferación de imágenes que, evidentemente, conducía a la dispersión y al alejamiento del verdadero sentido de la religión. "Habiendo vivido los últimos siglos una cierta preocupación antiprotestante, no ha sido fácil frenar la inflación del santoral. Las imágenes habian invadido el templo, siendo el principal o el único alimento de piedad para muchos fieles; mientras, el culto substancial quedaba relegado a segundo término. El mal no estaba en el hecho, sino en el exceso, exuberancia del culto de dulia en detrimento del culto de latría" ${ }^{4}$, señala mosén Juan Ferrando Roig.

Por to tanto, en la actualidad, varias imágenes han sido retiradas de los templos, pero, curiosamente, también se observa cómo en algunas iglesias de moderna arquitectura, para las que determinados escultores, alguno con prestigioso nombre, realizaron una serie de obras de línea avanzada, han visto sustituidas dichas obras por tradicionales imágenes de dudoso gusto y desafortunada ejecución. En líneas generales, podria decirse que en determinados sectores del clero, y también entre los fieles, reina la desorientación. José María de Azcárate hace referencia a este hecho al señalar que "no siempre la mediocre obra de arte está exenta de una cálida y popular devoción, mientras que obras ciertamente excelentes yacen olvidadas en los rincones, en los desvanes o en los lugares más apartados de las iglesias. Urge, por tanto, la necesidad de una orientación, de un adoctrinamiento, pues téngase presente que si estas normas hubiesen estado vigentes y se hubiesen seguido por las autoridades eclesiásticas de los siglos pasados habria desaparecido la mayor parte de nuestra imagineria medieval $»^{5}$.

J.M. de AGUILAR, O.P.: "La imagen religiosa. Consideraciones para una visión de conjunto', ARA, 1966, nं 9, pág. 18.

4 J. Fentando Rolg: "El problema de las imágenes", $A R A, 1966, n^{\circ} 9$, pág. 22.

J.M. de AzCARATE: "EI Arte al servicio de las devociones del pueblo cristiano", en Arte Sacro y Concilio Vaticano II, León, 1963, Junta Nacional Asesora de Arte Sacro, 1964, pág. 275. 
Otro factor a tenerse en cuenta es la armonía que debe existir entre la obra escultórica y su entorno arquitectónico, de tal forma que aquélla ocupe un lugar adecuado en el templo, centrando la atención de los fieles, pero, al mismo tiempo, haciendo resaltar debidamente sus valores artisticos para que éstos puedan ser apreciados; de lo contrario, un incorrecto emplazamiento ocasionaría la disminución de los mismos. José María Zunzunegui apunta lo siguiente en relación con este hecho: «Hay veces imágenes de mucha calidad e incluso de calidad extraordinaria que, sin embargo, por su localización desacertada resultan ellas mismas no gratas y apesadumbran el espacio sobre el que gravitan. Esta integración de la imagen en la arquitectura supone previsión de la imagen o de las imágenes desde el comienzo del proyecto y la más estrecha colaboración entre artista, arquitecto y responsable pastoral de la obra a todo lo largo del estudio y de la realización ${ }^{6}$.

Los temas iconográficos actuales están referidos a la figura de Jesucristo, la Virgen María, un vía crucis y el santo titular de la iglesia. En su representación se siguen diversas concepciones artísticas, que van desde una línea muy realista a otros planteamientos totalmente renovadores a base de formas muy estilizadas y apenas insinuadas; otras veces, por el contrario, se refleja un marcado expresionismo, siviéndose para ello el escultor de unas agudas, descarnadas e hirientes formas de irregulares superficies; en otros casos, se ha jugado con todas las posibilidades estéticas derivadas de la combinación de diferentes láminas de hierro y bronce, que, a su vez, albergan oquedades, por lo que se convierte el espacio en un material más; hay obras, de volúmenes aplomados, estáticos y monumentales, en las que se advierte una simplificación formal junto a una acusada rigidez y frontalismo; finalmente, algunos artistas se han servido de la abstracción al concebir un determinado tema religioso.

Podrian citarse varios nombres de escultores que han seguido esta tendencia renovadora, no sólo en cuanto a la interpretación de los temas iconográficos se refiere, sino también en la utilización de los nuevos materiales y técnicas, pero entre ellos nos referiremos a Ramón Lapayese, José María Subirachs, José Luis Sánchez y Jorge de Oteiza, para lo cual se citarán como ejemplo algunas de sus realizaciones artísticas.

Las obras de Ramón Lapayese oscilan entre un respeto a la figuración, aunque tendiendo siempre a un purismo formal, y un lenguaje claramente expresionista. En el interior de la Basilica del Valle de los Caídos, sobre la puerta de acceso y en un lugar en el que pasa totalmente desapercibida, se encuentra una imagen de la Virgen $(2,00 \mathrm{~m})$ (Fig. 1) realizada

\footnotetext{
"J.M. ZUNZUNEGUl: "Imágenes en el culto", ARA, 1978, n 58, pág. 117.
} 
en alabastro por este escultor en la segunda mitad de la década de los años cincuenta. La figura de María se levanta sobre un montículo de rugosa superficie, apreciándose junto a ella la forma abocetada de la Cruz del Valle que llega aproximadamente a la altura de las rodillas. En la ejecución de esta obra, que está dentro de la figuración tradicional, se aprecia una preocupación por valorar el volumen a través de la simplificación de planos que resaltan las esbeltas proporciones de las formas anatómicas, a la vez que ocasionan un marcado claroscuro, contrastando con el suave modelado que se observa en las superficies del rostro, manos y pies. La firma de Ramón Lapayese se puede leer sobre el cuerpo cúbico que sirve de base a esta imagen.

Esta obra, caracterizada por su clasicismo, equilibrio y armonía de lineas, contrasta con un Crucificado de madera de nogal (1,45 m) (Fig. 2) que este mismo escultor hizo para la madrileña parroquia de Nuestra Señora de Guadalupe, entre los años 1967 y 1968, aproximadamente. El cuerpo, que parece desgarrarse impulsado por su propio peso, sobrecoge por la acusada delgadez de las formas anatómicas, que han sido ejecutadas con un descarnado dramatismo; el cuello proyecta hacia delante una cabeza enmarcada por las dos bandas del cabello entre las que emerge un rostro barbado, de rasgos muy acusados y cadavéricos; la exagerada delgadez del cuerpo se acentúa con la posición de los brazos, que, formando un ángulo muy agudo, terminan en unas crispadas manos, sujetas al madero por unos clavos que traspasan las muñecas; los pies, surcados por largos tendones, acentúan el intenso dramatismo que encierra esta sobrecogedora obra, la cual es reproducción del Cristo que Ramón Lapaye presentó en la Bienal Hispano-Americana celebrada en Barcelona en 1955. El original es de escayola metalizada y patinada, con los cabellos de cobre rojizo, consiguiéndose con estos materiales un aspecto sanguinolento y macabro, semejante al de un cordero desollado, muy distinto al Crucificado tradicional. No obstante, debe señalarse que en el realizado para esta parroquia, el escultor, si bien se mantuvo dentro de una línea marcadamente expresionista, hizo una serie de concesiones por tener en cuenta que iba a ser destinado al culto de una iglesia.

La actividad de José María Subirachs en el terreno de ia escultura religiosa es también muy relevante, siendo buena prueba de ello la fachada y puertas del santuario de la Virgen del Camino, en León, que fue inaugurado en 1961. El apostolado de dicha fachada, junto a la figura de Maria, es un claro exponente de la extraordinaria fuerza expresiva que este original artista sabe transmitir a su obra, que ha sido concebida, en esta ocasión, magistralmente en bronce.

En 1965 realizó para la capilla del colegio de los Sagrados Corazones, 
en Madrid, un conjunto escultórico en el que destaca la representación de los Sagrados Corazones de Jesús y de Maria.

Bajo esta advocación se han realizado diversas imágenes que se ciñen fielmente a su iconografía, siendo la mayoría de las veces muy realistas y convencionales. Pero conviene señalar, como dice mosén Juan Ferrando Roig que: "La imagen sagrada debe desprenderse de la realidad, deshumanizarse, para expresar mejor el sentido sagrado y trascendente. La realidad tan sólo debe ser sugerida. Nótese que las imágenes menos logradas suelen ser aquellas de cuyos personajes conservamos el retrato y mayor cantidad de detalles físicos. No se ha logrado la imagen del Sagrado Corazón debido a ese empeño por "humanizar" un símbolo"?. Indudablemente, y sin ánimo de herir algunas susceptibilidades, no es una de las imágenes más acertadas, salvo raras excepciones, precisamente aquellas en las que, como en los dos ejemplos que a continuación se describen, el escultor ha obrado con una mayor libertad plástica, apartándose de un acusado naturalismo para conseguir, aún dentro de la figuración, una mayor expresividad a través de alargadas y, al mismo tiempo, descarnadas formas anatómicas, de superficies irregulares. Sobre la pared de la derecha de la capilla del colegio anteriormente citado, está situada una escultura en bronce del Sagrado Corazón de Maria, de tamaño mayor que el natural. La Virgen, con las manos hacia arriba, enmarcando el corazón, aparece cubierta por un manto bajo el que se ocultan las alargadas formas del cuerpo, adquiriendo éste un cierto volumen como consecuencia del plegado de las telas que lo cubren, si bien a la altura de las piernas, los pliegues caen verticalmente, acentuando la rigidez de la figura, a la vez que el curioso alargamiento del cuello realza aún más la estilización de la misma.

Fuera de la capilla, a la derecha de la puerta de acceso a la misma, se encuentra una escultura en bronce del Sagrado Corazón de Jesús $(1,45 \mathrm{~m})$ (Fig. 3). Su alargado cuello sostiene una cabeza rodeada por una forma circular que adopta la apariencia de un halo luminoso; el rostro, barbado y anguloso, está enmarcado por el cabello que cae en dos bandas sobre la espalda; un manto cubre parte del cuerpo en el que se ha representado el corazón sobre unas esquemáticas y descarnadas formas anatómicas; la mano derecha está en actitud de bendecir, mientras que el brazo izquierdo se mantiene pegado al cuerpo, con lo que se acentúa el verticalismo y estilización de la figura que, al igual que la imagen de la Virgen anteriormente descrita, es de estilo muy expresionista.

José Luis Sánchez, autor de un importante número de obras religiosas, hizo para la madrileña parroquia de Nuestra Señora de Moratalaz un

\footnotetext{
J. Ferrando Roig, Art. cit., pág. 24.
} 
conjunto escultórico que data de mediados de los años sesenta y en el que destaca un Crucificado (Fig. 4) y la representación de la Virgen (Fig. 5) bajo la advocación que da nombre a este templo.

El primero se destaca en el testero principal de la iglesia, situado sobre una estructura de madera que ocupa el centro de un entrante en el muro. Su tamaño es mayor que el natural y está realizado en cemento metalizado. El paño que le cubre, anudado a la altura de las caderas, cae hasta las rodillas, acentuando la verticalidad del cuerpo de Jesucristo, en el que se advierte una simplificación de las formas anatómicas de clara concepción frontal.

En el exterior de la iglesia se ha situado sobre un basamento cúbico una escultura de bronce que representa a Nuestra Señora de Moratalaz en tamaño natural. La Virgen está sentada sosteniendo una casa que simboliza el barrio y a su lado, de pie, se encuentra el Niño Jesús con una paloma en la mano derecha. Nuevamente aparece en esta escultura lo que es una constante en la obra de José Luis Sánchez: la verticalidad y el frontalismo, la valoración de la masa, del volumen, junto a unas formas anatómicas reducidas a los planos esenciales.

Finalmente, el vanguardismo radical de Jorge de Oteiza, que quiere romper con lo figurativo, define su inquietante y recia personalidad artistica, reflejada en el proyecto de un apostolado para la Basílica de Aránzazu, el cual seria inicialmente rechazado en 1954 por su linea vanguardista.

La capilla del Instituto Politécnico Masculino de Santa María del Castillo, en Buitrago (Madrid), alberga una de sus obras, situada a la izquierda del presbiterio. Es una impresionante escultura, fechada en el año 1973, que representa a Nuestra Señora del Castillo $(2,35 \mathrm{~m}$ ) (Fig. 6). El gran podio sobre el que se levanta acentúa aún más sus magníficas proporciones. Todo en ella es fuerza, aplomo, sobrecogedora en lo que se podria denominar volumen ciclópeo. Ha de valorarse no el detalle, que no existe, sino el expresivo conjunto lleno de rotundas formas, de las que emana un gran vitalismo y total energia. Posiblemente nos encontramos ante una obra que tendrá sus detractores, que no puede ser fácilmente comprendida y que, sin embargo, ocupa el lugar que le corresponde dentro de esta capilla con la que guarda una total armonia.

La aportación escultórica de estos cuatro artistas, Ramón Lapayese, José María Subirachs, José Luis Sánchez y Jorge de Oteiza, constituye un claro exponente de la renovación operada en nuestro pais dentro del arte sacro, y de manera más concreta testimonia una nueva concepción de la imagen que, paulatinamente, se va adaptando a las necesidades artísticas de nuestro siglo, en el que se advierte un firme propósito de renovación, al que no debe ser ajena la escultura religiosa. 


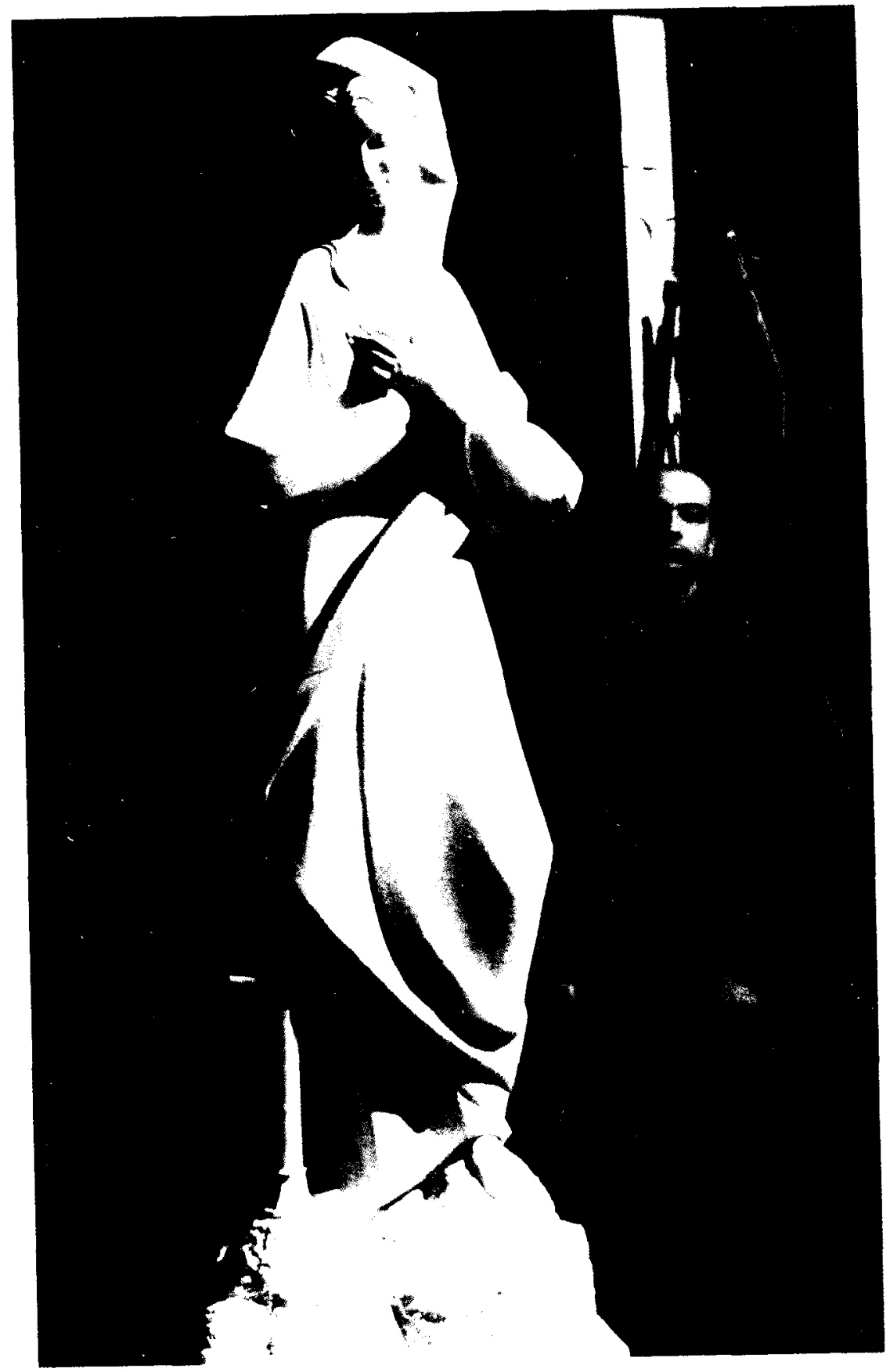

Fig. 1. Ramón Lapayese. Virgen del Valle de los Caidos. 


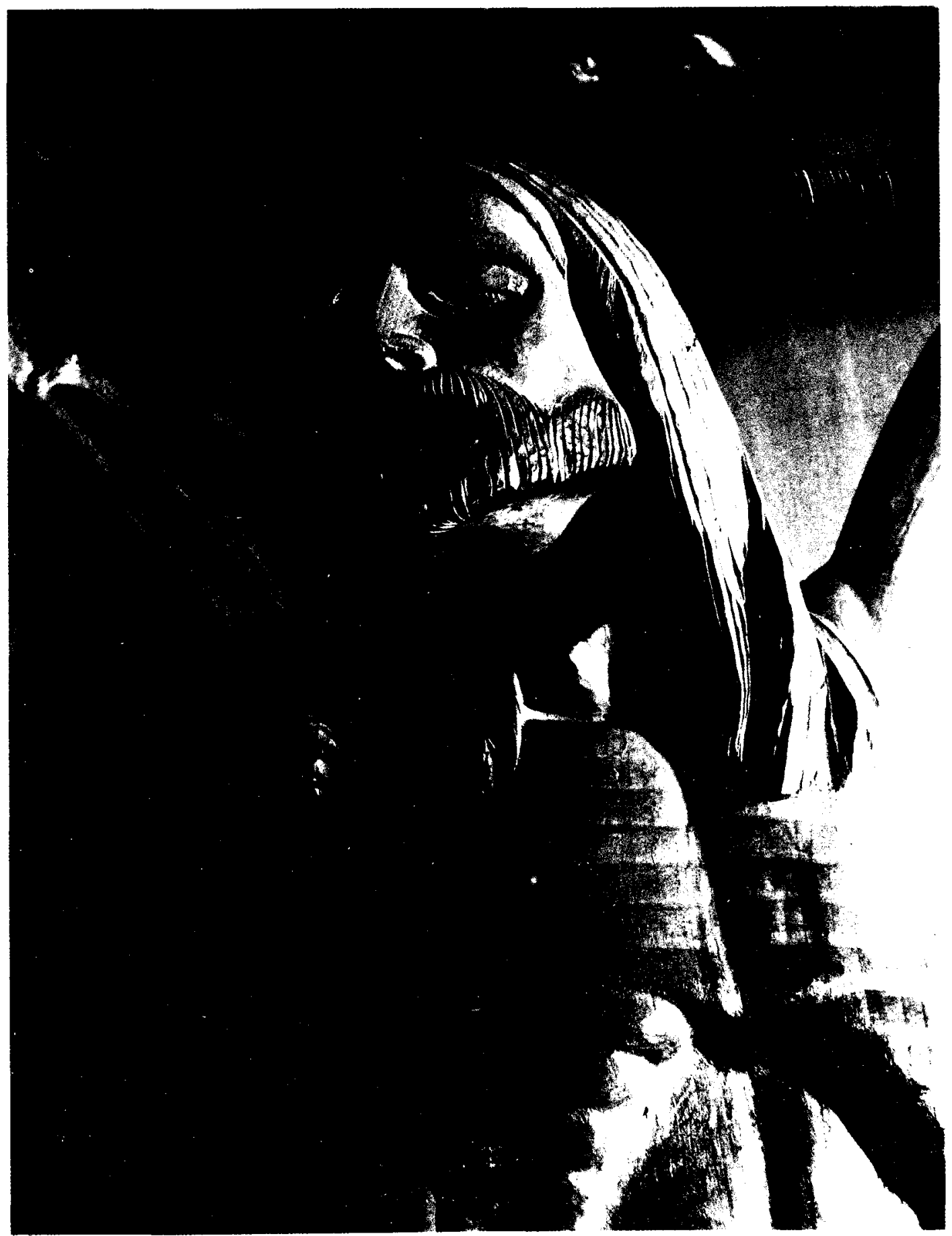

Fig. 2. Ramón Lapayese. Crucificado (detalle). Parroquia de Nuestra Señora de Guadalupe, Madrid. 


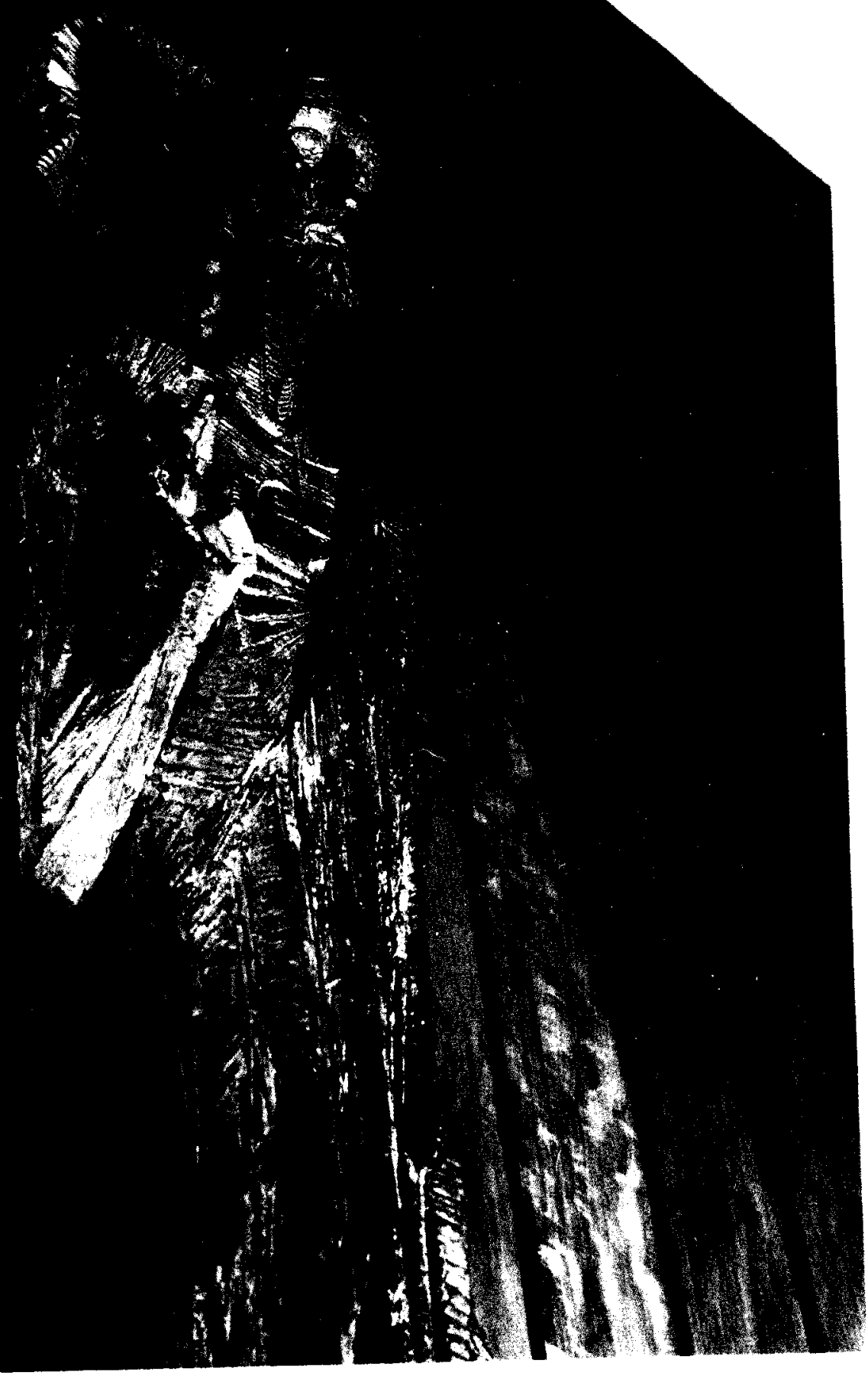

Fig. 3. José Maria Subirachs. Sagrado Corazón de Jesús (detalle). Colegio de los Sagrados Corazones, Madrid. 


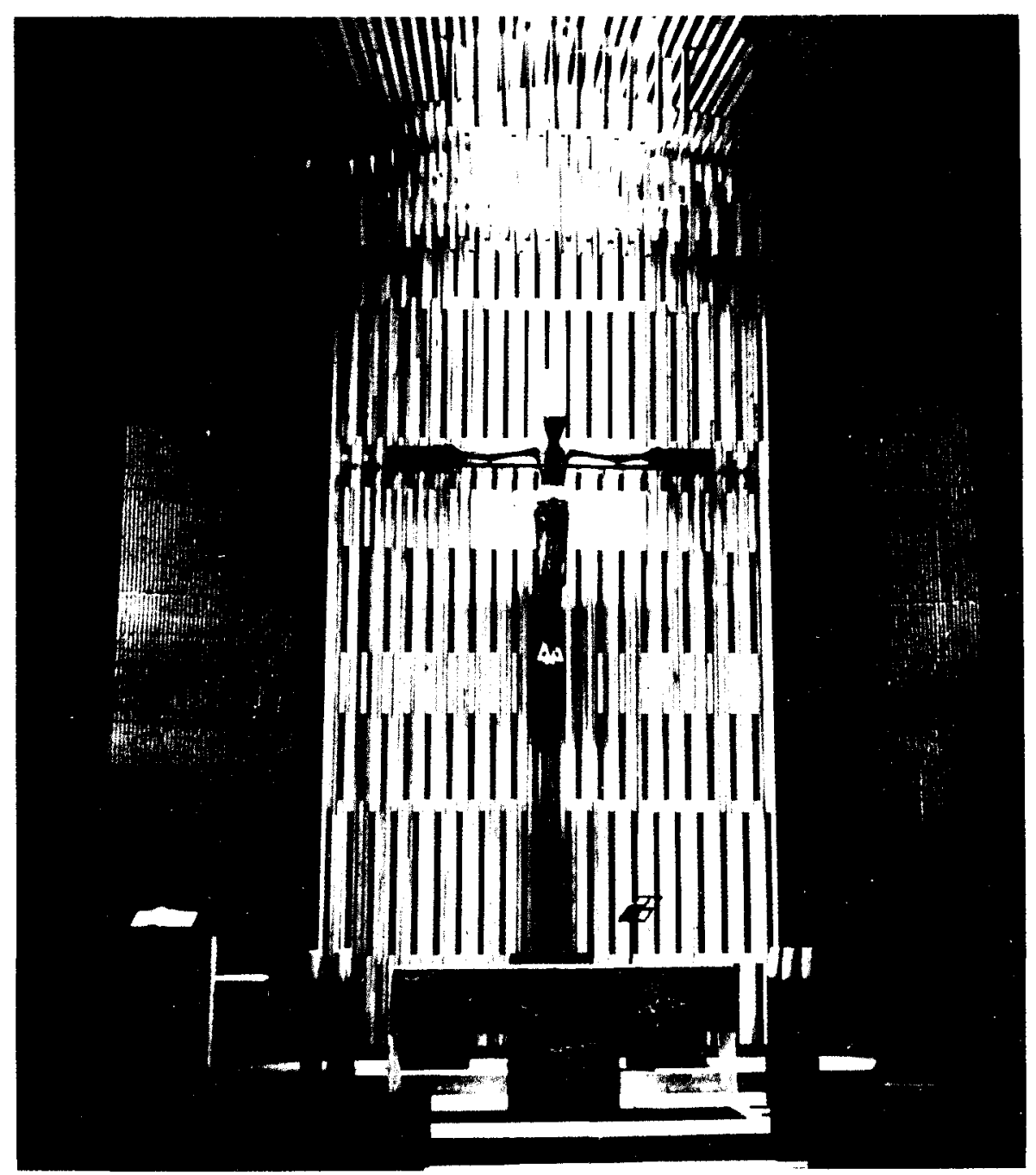

Fig. 4. José Luis Sánchez. Crucificado. Parroquia de Nuestra Señora de Moratalaz, Madrid. 


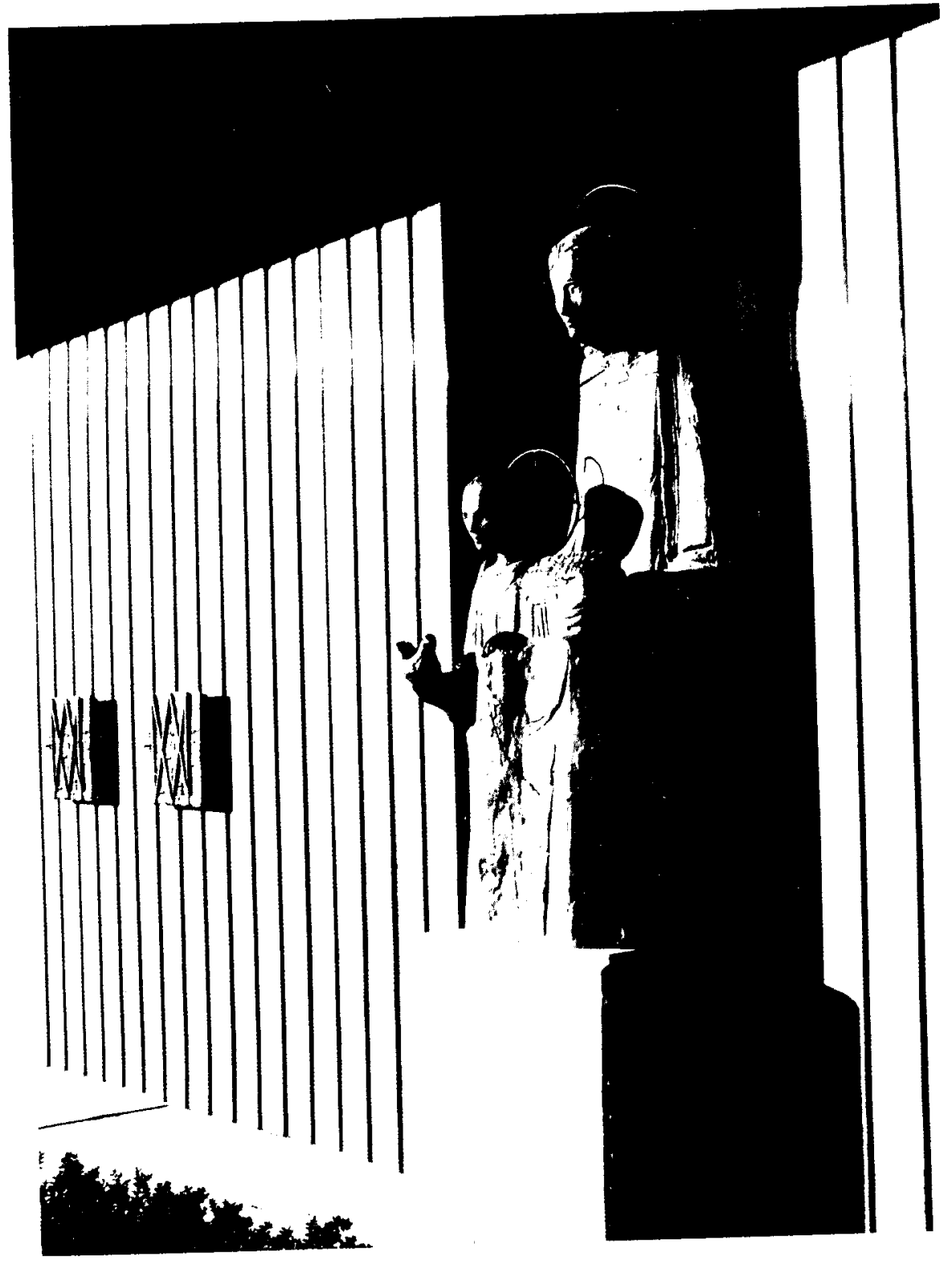

Fig. 5. José Luis Sánchez. Nuestra Señora de Moratalaz. Parroquia de Nuestra Señora de Moratalaz, Madrid. 


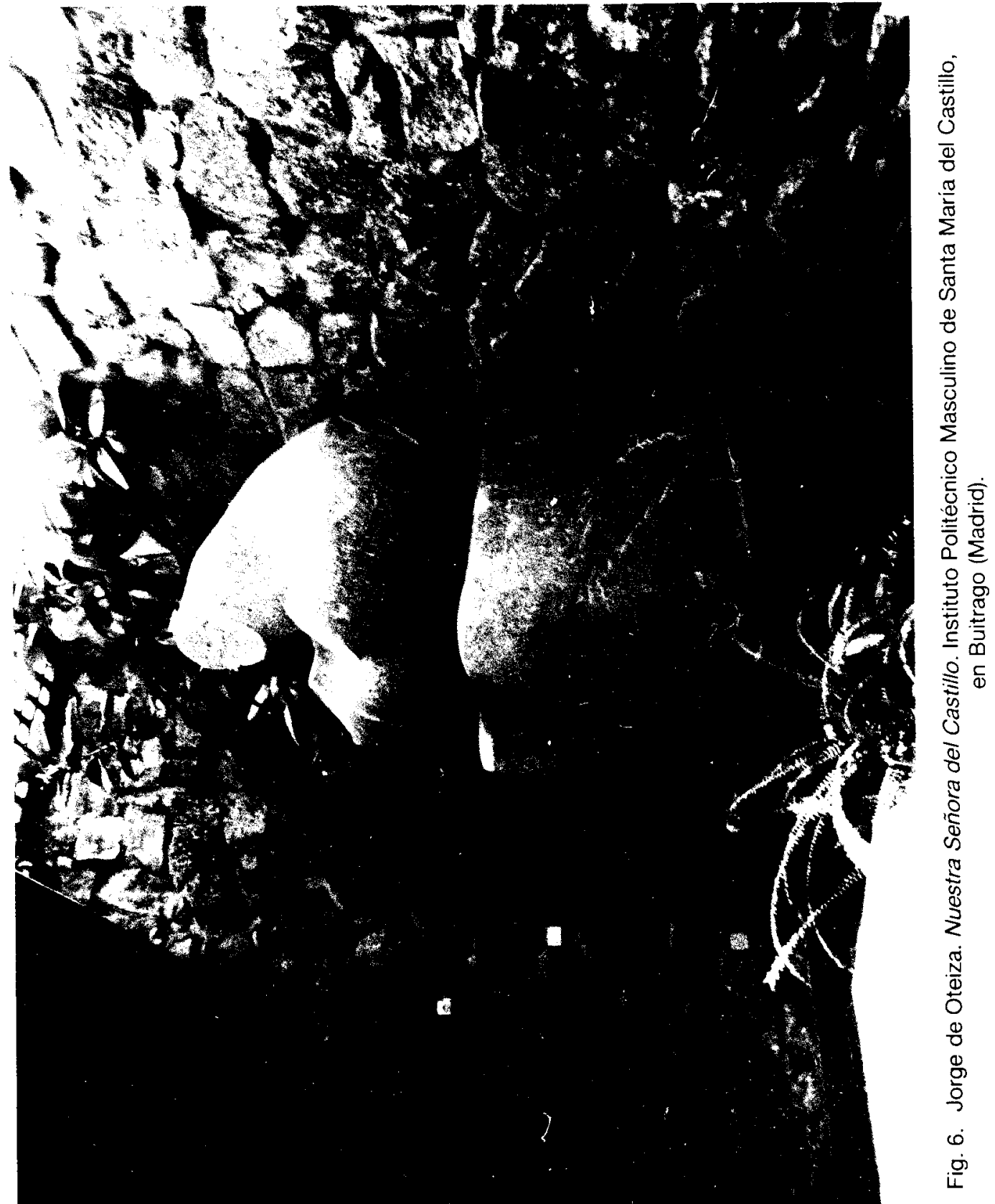

